\title{
Response: Commentary: The Impact of Climate Change on Landslides in Southeastern of High-Latitude Permafrost Regions of China
}

\author{
Wei Shan ${ }^{1,2 *}$, Zhichao $\mathrm{Xu}^{1}$, Ying Guo ${ }^{1,2}$ and Chengcheng Zhang ${ }^{1,2}$ \\ ${ }^{1}$ Institute of Cold Regions Science and Engineering, Northeast Forestry University, Harbin, China, ${ }^{2}$ Field Scientific Observation \\ and Research Station of the Ministry of Education - Geological Environment System of Permafrost Area in Northeast China (FSSE- \\ PFNEC), Harbin, China
}

Keywords: climate change, high-latitude permafrost, permafrost degeneration, landslide movement, pore water pressure

\section{A Commentary on}

OPEN ACCESS

Edited by:

Davide Tiranti,

Agenzia Regionale per la Protezione

Ambientale, Italy

Reviewed by:

Fabio Matano,

National Research Council (CNR), Italy

Stefano Luigi Gariano,

Institute for Geo-Hydrological

Protection (IRPI), Italy

${ }^{*}$ Correspondence:

Wei Shan

Shanwei456@163.com

Specialty section:

This article was submitted to

Quaternary Science, Geomorphology

and Paleoenvironment,

a section of the journal

Frontiers in Earth Science

Received: 11 December 2020

Accepted: 21 January 2021

Published: 22 March 2021

Citation:

Shan W, Xu Z, Guo Y and Zhang C (2021) Response: Commentary: The Impact of Climate Change on Landslides in Southeastern of HighLatitude Permafrost Regions of China. Front. Earth Sci. 9:638578. doi: 10.3389/feart.2021.638578
The Impact of Climate Change on Landslides in Southeastern of High-Latitude Permafrost Regions of China

by Shan, W., Hu, Z., Guo, Y., Zhang, C., Wang, C., Jiang, H., et al. (2015). Front. Earth Sci. 3:7. doi:10. 3389/feart.2015.00007

Affected by global warming and regional geological conditions, the combined effects of permafrost melting, and extreme weather events may induce landslides in permafrost regions (Wang et al., 2018; Patton et al., 2019; Chen et al., 2020). The research team took the Bei'an to the Heihe expressway, to the study area which is located in the southern boundary of the permafrost zone in northeastern China. Through comprehensive investigation and fixed-point monitoring, the influence of climate change on landslides in the study area was analyzed. The results show that permafrost melting, and seasonal concentrated precipitation are the main causes of landslide movement (Shan et al., 2015).

Juanico (2016) believes that human engineering activities, rapid population growth, rapid urbanization, and an urban heat island effect in Sunwu, near the study area, may be important reasons for the increase in air temperature in the study area. To improve the problems mentioned above, the research team installed meteorological stations near the study area, and, combined with data from the National Meteorological Station on surface temperature in the Sunwu area and MODIS data, it was found that the increasing trend of surface temperature obtained from the National Meteorological Station in Sunwu was higher than that obtained from the MODIS data, which may be due to the influence of the urban heat island effect and human activities on the surface temperature observation points of the National Meteorological Station in Sunwu. However, the areas far away from the densely populated areas of Sunwu are relatively less affected (Study area k161 +440 is $9.5 \mathrm{~km}$ away from the edge of Sunwu, k177 + 550 is $16.9 \mathrm{~km}$ away from the edge of Sunwu), as shown in Figures 1A,G. In addition, since 2004, the surface melting index near the study area has increased significantly; the surface freezing index and the surface freezing number have shown a significant downward trend. Affected by factors such as rising air temperature, the remaining shallow permafrost in the study area may be completely thawed, as shown in Figure 1B (Guo et al., 2020; Shan et al., 2020a; Shan et al., 2020b).

In addition, China's population, economy, and urbanization are mainly concentrated in eastern and southern areas, while population growth and economic development in the Sunwu 

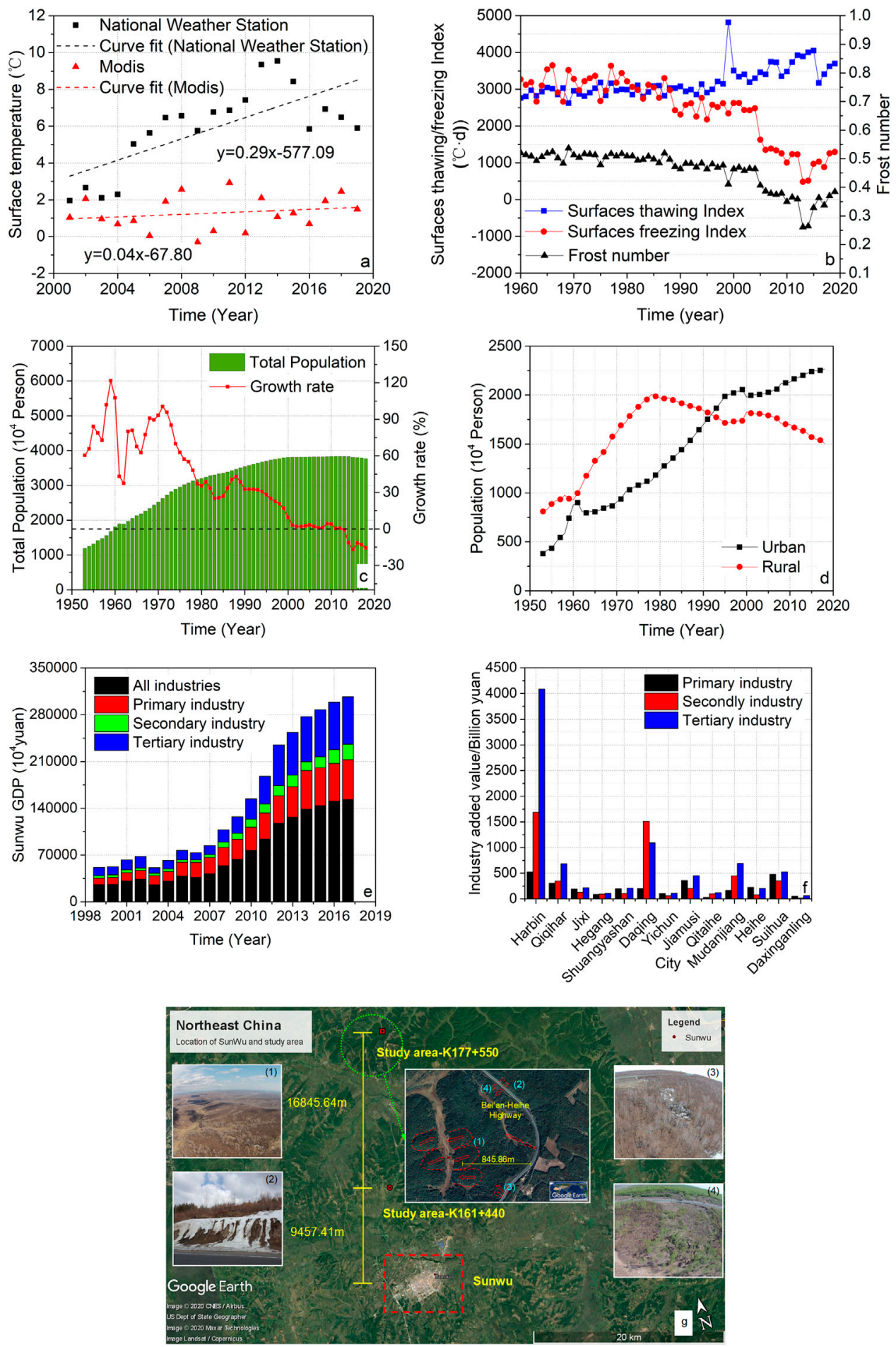

FIGURE 1 | Permafrost degradation, population, urbanization, and landslide distribution near the study area. (A) Surface temperature changes of the Sunwu area, including the data of Sunwu national weather station and MODIS data (Guo et al., 2020; Shan et al., 2020b). (B) Changes of surface freezing, thawing index, and freezing number from 1960 to 2019. The calculation method is shown in reference (Guo et al., 2020; Shan et al., 2020b). (C) Population changes and the growth rate of Heilongjiang Province, China. (D) Changes of the urban population and rural population in Heilongjiang Province. (E) GDP of different industries in Sunwu County (Primary industry: agriculture, forestry, animal husbandry, fishery, etc., Secondary industry: mining, manufacturing, electricity, gas and water production and supply, construction, etc., Tertiary industry: transportation, storage and postal industry, information transmission, computer service and software industry, etc.). (F) Added value of different industries in different cities in Heilongjiang Province (Primary industry, Second industry, Tertiary industry). (G) The straight-line distance between Sunwu County and the observation points at K161 + 440 and $\mathrm{K} 177+550$ in the study area and the pictures of landslides at K177 + 550 [landslides (1), (2), (3), (4)] 
(located in Heihe City, Heilongjiang Province) in northern China are relatively slow, and some areas even show negative growth (Hua, 2018). Since 1971, the population growth rate of Heilongjiang Province has shown a gradual decline, and there has been a negative population growth from 2013 to 2018 (Figure 1C). Rural populations are moving to urban areas in large numbers, and the population of rural areas has significantly decreased (Figure 1D). In addition, Heihe City accounts for a relatively small proportion of industries in Heilongjiang Province (Figure 1F). The Sunwu area is mainly dominated by primary and tertiary industries. Although the proportion of secondary industry has increased (Figure 1E), the overall trend of change is slow. Therefore, urbanization and industrialization of the Sunwu area are relatively slow, and the corresponding urban heat island effect is relatively weak and has little impact on the surrounding environment. In addition, although the development of primary industries in the Sunwu area will cause damage to some areas, there are few population activities near the study area, and land for agriculture and forestry is scarce, so the development of primary industries has relatively little impact on the environment of the study area.

Juanico (2016) believes that human activities can lead to landslides. In addition to ongoing construction works, vehicle vibrations along the highway may generate enough power to trigger landslides in previously undisturbed areas (Moreiras, 2004). Continuous precipitation, even at non trend rates, combined with vibration loads, can drive landslide activity regardless of permafrost thawing (Juanico et al., 2008).

The vehicle load on expressways is mainly a point vibration, and the vibration intensity attenuation formula is shown in Eq. 1 (Xia, 2010). Through Eq. 1, it can be seen that the damping ratio of soil has a significant impact on vibration intensity attenuation.

$$
A_{r}=A_{0} r^{-n} e^{-2 \pi f \beta_{c} r / c}
$$

Where, $A_{0}$ is the amplitude of the base point near the vibration source $(m) ; A_{r}$ is the amplitude of the place where the distance from the vibration source is $r(\mathrm{~m}) ; \beta_{\mathrm{c}}$ is the damping ratio of the soil medium; $f$ is the vibration frequency; $c$ is the propagation velocity; $n$ is the coefficient, $n=0.5$ for surface wave, and $n=2$ for solid wave in elastic half space.

Studies have shown that the combination of coarse and fine particles within a moderate range of soil (Cui and Jing, 2019; Song et al., 2020) and the melting of frozen soil will increase the damping ratio of the soil (Sun et al., 2017). The soil composition in the study area contains both fine-grained structures such as clay and coarsegrained structures such as gravelly sandstone. After observation, it was found that the frozen soil layer near the study area is gradually degrading (Shan et al., 2020a), which leads to a higher damping ratio of the soil in the study area, resulting in a faster attenuation of traffic load and a smaller spreading distance. In addition, statistics on landslides near K177 + 550 in the study area found that not only do landslides exist in the area close to the highway, but also in areas far away from the road $(845.86 \mathrm{~m})$. There is basically no human activity, so the impact of traffic vibration load on the landslide in the study area is relatively small.
Matano (2016) believes that the interaction between the effects of ongoing climate change and construction of the highway on the permafrost conditions was not addressed in the study. Further, the slope instabilities along non-frozen slope sections induced by highway construction and extension work should also be considered.

In response to the above problems, we have observed the permafrost thickness, air temperature, and ground temperature near study area k161 + 440 for many years and found that the ongoing climate change and construction of the highway led to a rise in the ground temperature, and then led to the gradual degradation of the permafrost (Guo et al., 2020). In addition, through the investigation, it was found that for the slope section in the non-frozen area, the construction of a highway will disturb the original soil structure and cause new landslides, and for the old landslide area it will cause the old landslide to slide again (Shi et al., 2014; Wang et al., 2019; Guo et al., 2021; Shan et al., 2021).

Juanico (2016) believes that the growth process of human settlements can directly or indirectly induce geomorphic evolution on a local scale, and greenhouse gas emissions from industrial production leads to climate warming, which may increase the speed of geomorphic processes such as landslides.

We found that during every spring in the study area, a large amount of methane gas is released, which mainly comes from the release of geological methane and microbial methane production in permafrost, and the release of this part of greenhouse gas will lead to an increase of air temperature, it will accelerate the degradation of permafrost, will then play a role in promoting global warming, and also lead to geomorphic changes (Shan et al., 2020a; Shan et al., 2020b; Shan et al., 2021).

In summary, it can be seen that human engineering activities, the urban heat island effect, rapid population growth, and rapid urbanization have relatively little impact on the air temperature rise in the study area. The air temperature rise near the study area is mainly affected by global warming and the release of greenhouse gases after the degradation of permafrost. The degradation of the permafrost, caused by the air temperature rise and human engineering activities, will further lead to landslides. The main driving force behind landslides in the study area is permafrost degradation caused by global warming.

\section{AUTHOR CONTRIBUTIONS}

WS, ZX, and YG design research and paper writing; ZX and CZ for data processing and approved it for publication.

\section{ACKNOWLEDGMENTS}

We thank the National Natural Science Foundation of China (41641024) for providing financial support and the Field scientific observation and research station of the Ministry of Education Geological environment system of permafrost area in Northeast China (FSSE-PFNEC). 


\section{REFERENCES}

Chen, X. Y., Zhang, L. L., Zhang, L. M., Zhou, Y., Ye, G., and N., Guo (2020). Modelling rainfall-induced landslides from initiation of instability to postfailure. Comput. Geotech. 129, 10387. doi:10.1016/j.compgeo.2020.103877

Cui, K., and Jing, X. (2019). Effect of coarse grain content on the dynamic shear modulus and damping ratio of mixed soil under seismic load in western Sichuan. China J. Highw. Trans. 32, 123-131(.) [in Chinese, with English summary]. doi:10.19721/j.cnki.1001-7372.2019.12.013

Guo, Y., Shan, W., Chengcheng, Z., Hu, Z., Wang, S., and Gao, J. (2020). Monitoring of permafrost degradation along the Bei'an-Heihe expressway in China. Bull. Eng. Geol. Environ. 16, 1-10. doi:10.1007/s10064-020-01919-3

Guo, Y., Shan, W., Xu, Z., Wang, C., and Wang, S. (2021). Identification old landslides in permafrost degradation area in northeast China by difference distribution of surface trees. WLF 2020. ICL contribution to landslide disaster risk reduction. Berlin, Germany: Springer.

Hua, H. (2018). The research on influencing factors and rationality of spatial distribution of population in China. Master's dissertation. Shanghai (China): East China Normal University.

Juanico, D. E. O. (2016). Commentary: the impact of climate change on landslides in southeastern of high-latitude permafrost regions of China. Front. Earth Sci. 4, 1-3. doi:10.3389/feart.2016.00011

Juanico, D. E. O., Longjas, A., Batac, R., and Monterola, C. (2008). Avalanche statistics of driven granular slides in a miniature mound. Geophys. Res. Lett. 35, L035567. doi:10.1029/2008GL035567

Matano, F. (2016). Commentary: the impact of climate change on landslides in southeastern of high-latitude permafrost regions of China. Front. Earth Sci. 4, 1-3. doi:10.3389/feart.2016.00022

Moreiras, S. M. (2004). Landslide incidence zonation in the Rio Mendoza valley, Mendoza province, Argentina. Earth Surf. Process. Landf. 29, 255-266. doi:10.1002/esp.1056

Patton, A. I., Rathburn, S. L., and Capps, D. M. (2019). Landslide response to climate change in permafrost regions. Geomorphology 340, 116-128. doi:10. 1016/j.geomorph.2019.04.029

Shan, W., Guo, Y., and Zhang, C. C. (2020a). "Understanding the geological environmental risks of permafrost degradation:environmental and engineering geology in permafrost areas in northeast China," in IRDR working paper on scientific output of disaster risk reduction. Beijing: IRDR

Shan, W., Xu, Z. C., Guo, Y., Zhang, C., Hu, Z., and Wang, Y. (2020b). Geological methane emissions and wildfire risk in the degraded permafrost area of the Xiao Xing'an Mountains, China. Sci. Rep. 10 (1), 21297. doi:10. 1038/s41598-020-78170-Z

Shan, W., Hu, Z. G., Guo, Y., Zhang, C., Wang, C., Liu, Y., et al. (2015). The impact of climate change on landslides in southeastern of high-latitude permafrost regions of China. Front. Earth Sci. 24, 1-11. doi:10.3389/feart. 2015.00007

Shan, W., Zhang, C. C., Guo, Y., Shan, M., Zeng, X., and Wang, C. (2021). Climate change and surface deformation characteristics in degradation area of permafrost in Lesser Khingan mountain, China. WLF 2020. ICL contribution to landslide disaster risk reduction. Berlin, Germany: Springer.

Shi, X. G., Liao, M., Wang, T., Zhang, L., Shan, W., Wang, C., et al. (2014). Expressway deformation mapping using highresolution TerraSAR-X images. Remote Sens. Lett. 5, 194-203. doi:10.1080/2150704X.2014.891774

Song, X. L., Zhang, J., and Zhang, P. (2020). Experimental study on dynamic properties of clayey sand. Chin. J. Underground Space Eng. 16, 1383-1390. [in Chinese, with English summary].

Sun, R., Yu, X.-B., Yuan, X.-M., Meng, S.-J., Chen, Z.-S., and Wang, M. (2017) Method for dynamic shear moduli and damping ratio of typical soils in seasonal frozen region. Chin. J. Geotech. Eng. 39, 116-128(.) [in Chinese, with English summary]. doi:10.11779/CJGE201701010

Wang, S., Xu, B., Shan, W., Shi, J., Li, Z., and Feng, G. (2019). Monitoring the degradation of island permafrost using time-series InSAR technique: a case study of Heihe, China. Sensors 19, 1364. doi:10.3390/s19061364

Wang, Y., Lin, Q., and Shi, P. (2018). Spatial patern and influencing factors of landslide casualty events. J. Geogr. Sci. 28, 259-274. doi:10.1007/s11442-0181471-3

Xia, H. (2010). Traffic induced environmental vibration and controls. Beijing, China: Science Press. [in Chinese, with English summary].

Conflict of Interest: The authors declare that the research was conducted in the absence of any commercial or financial relationships that could be construed as a potential conflict of interest.

Copyright (C) 2021 Shan, Xu, Guo and Zhang. This is an open-access article distributed under the terms of the Creative Commons Attribution License (CC $B Y)$. The use, distribution or reproduction in other forums is permitted, provided the original author(s) and the copyright owner(s) are credited and that the original publication in this journal is cited, in accordance with accepted academic practice. No use, distribution or reproduction is permitted which does not comply with these terms. 